\title{
Methodo Penido: estado e município na luta pela alfabetização na sociedade de Minas Gerais, no final do século XIX.
}

\author{
Methodo Penido: state and municipality in the struggle for literacy training in the society of \\ Minas Gerais at the end of the nineteenth century.
}

Methodo Penido: estado y municipio en la lucha por la alfabetización en la sociedad de Minas Gerais, a finales del siglo XIX.

Wenceslau Gonçalves Neto ${ }^{1}$; Carlos Henrique de Carvalho ${ }^{2}$

\section{Resumo}

A partir da década de 1890, em Minas Gerais, observa-se preocupação governamental com a instrução pública, tentando superar o analfabetismo e criar estrutura para o progresso da educação, com edição da lei de instrução pública (1892) e do regulamento escolar (1893). Estimulou-se também outras práticas, como a publicação do Methodo Penido, de Agostinho Penido, que foi publicado em 1890 e largamente distribuído entre as escolas mineiras. No entanto, não se tem notícia de qualquer exemplar remanescente desse método e nem de estudos sobre seu autor. Foram utilizadas fontes do Arquivo Público Mineiro e do Arquivo Municipal de Ouro Preto. Buscou-se recuperar a trajetória de Agostinho Penido, do processo de avaliação, premiação e adoção do método por parte do governo e da difusão posterior do mesmo. Percebe-se a importância da alfabetização na sociedade mineira do início da República e a participação de intelectuais da educação na busca de alternativas para seu enfrentamento.

Palavras-chave: Alfabetização, Método Penido, Minas Gerais.

1 Doutor em História pela Universidade de São Paulo. Professor dos Programas de Pós-Graduação em Educação da Universidade de Uberaba e da Universidade Federal de Uberlândia. Bolsista Produtividade em Pesquisa do CNPq e do Programa Pesquisador Mineiro da FAPEMIG. E-mail: wenceslau@ufu.br.

${ }^{2}$ Doutor em História pela Universidade de São Paulo. Professor da Faculdade de Educação e do Programa de Pós-Graduação em Educação da Universidade Federal de Uberlândia. Bolsista Produtividade em Pesquisa do CNPq e do Programa Pesquisador Mineiro da FAPEMIG. E-mail: carloshcarvalho06@yahoo.com.br. 


\begin{abstract}
Beginning in the 1890s in Minas Gerais, Brazil, a governmental concern arose regarding general public education, with an attempt to overcome illiteracy and create structures for progress in education through drafting a law of public education (1892) and regulation of schools (1893). Other practices were also encouraged, such as publication of the Methodo Penido (Penido Method) by Agostinho Penido, which was published in 1890 and widely distributed among schools in Minas Gerais. However, no remaining copy of this method is known, nor studies on its author. This study used sources of the Public Archives of Minas Gerais and the Municipal Archives of Ouro Preto. We aimed to recover the trajectory of Agostinho Penido, the process of evaluation, granting awards, and adoption of the method on the part of the government, and the subsequent spread of the method. The importance of literacy training in the society of Minas Gerais at the beginning of the Republic and the participation of intellectuals in education in seeking alternatives to deal with this issue are in evidence.
\end{abstract}

Keywords: Literacy training, Penedo Method, Minas Gerais

\title{
Resumen
}

A partir de la década de 1890, en el estado de Minas Gerais, se observa preocupación gubernamental con la instrucción pública, intentando superar el analfabetismo y crear estructura para el progreso de la educación, con edición de la ley de instrucción pública (1892) y del reglamento escolar (1893). Se estimuló también otras prácticas, como la publicación del Methodo Penido, de Agustín Penido, que fue publicado en $1890 \mathrm{y}$ ampliamente distribuido entre las escuelas de Minas Gerais. Sin embargo, no se tiene noticia de cualquier ejemplar remanente de ese método y ni de estudios sobre su autor. Se utilizaron fuentes del Arquivo Público Mineiro y del Arquivo Municipal de Ouro Preto. Se buscó recuperar la trayectoria de Agustín Penido, del proceso de evaluación, premiación y adopción del método por parte del gobierno y de la difusión posterior del mismo. Se percibe la importancia de la alfabetización en la sociedad de Minas Gerais del inicio de la República y la participación de intelectuales de la educación en la búsqueda de alternativas para su enfrentamiento.

Palabras clave: Alfabetización, Método Penido, Minas Gerais 
A reorganização de uma sociedade é desafio hercúleo em quaisquer circunstâncias ou lugares e a História nos auxilia, oferecendo registros sobre experiências que se multiplicaram ao longo do tempo, sejam causadas por transformações violentas ou pela vontade expressa do povo. O Brasil experimentou várias dessas situações de passagem em sua trajetória no século XIX, entre os quais destacaríamos a chegada da família real portuguesa em 1808, a independência de Portugal em 1822, a libertação dos escravos em 1888 e a proclamação da República em 1889, sendo esta última a que nos interessa mais diretamente.

Ao passar por todos esses momentos de crise e transformação - e por diversos outros, como a abdicação do primeiro imperador, os movimentos separatistas, a guerra do Paraguai, etc - o país foi amadurecendo e procurando novos caminhos que permitissem superar os entraves que vinham sendo enfrentados. Em muitos casos alcançou sucesso, mas em vários não conseguiu avançar para os patamares necessários à continuidade do processo de desenvolvimento, como implementar a industrialização, incorporar o negro liberto ou criar um sistema de ensino que garantisse as bases da montagem de uma nacionalidade, dos princípios da cidadania e a preparação da mão de obra necessária a uma sociedade que aspirava fazer parte do concerto das nações desenvolvidas. Infelizmente, nesse caso, não se conseguiu nem superar a barreira inicial do analfabetismo, que abarcava mais de $80 \%$ da população no alvorecer da República.

Em que pesem a avançada proposta de ensino gratuito contida no artigo 77 da Constituição de 1824, os objetivos da lei das escolas de primeiras letras de 1827, das várias reformas empreendidas, o período imperial não foi muito pródigo em boas notícias para o campo da educação, embora se deva reconhecer que, em seus estertores, o debate sobre a necessidade da formação de um sistema nacional de ensino estava colocado. Caberia, no entanto, à República o enfrentamento da questão, na preparação do país para o século XX que se avizinhava e, com ele, as promessas de um futuro marcado pelo ritmo do progresso. O tema da educação popular, todavia, ficou fora das preocupações dos que trabalharam na Constituição federal de 1891, que estabeleceu apenas a laicidade do ensino mas não propôs diretrizes para o que poderia ser uma educação nacional. Dessa forma, a responsabilidade pela instrução elementar da população recaiu sobre os estados que puseram em execução suas propostas específicas, de acordo com suas condições financeiras e/ou apreço das elites regionais pela educação. Como eram 20 os estados à época, teríamos, se todos tivessem logrado sucesso em seus intentos, 2 dezenas de sistemas de ensino e não um projeto nacional de educação.

É no âmbito dessas múltiplas transformações que educação e escolarização entram na pauta dos entes da recém criada federação brasileira, pois reformar a escola pública passa a ser medida necessária e urgente, por se constituir no espaço capaz de adequar a sociedade ao projeto republicano de civilização, ainda que as ações nesta direção, desencadeadas nos estados, tenham sido bem assimétricas entre eles. Em Minas Gerais observa-se um início titubeante, em que, segundo Paulo Krüger Corrêa Mourão, "Houve decretos sem grande importância, com dispositivos diversos sobre a instrução elementar que prosseguia com as normas ainda não modificadas do tempo do Império"”. Essa situação refletia as especificidades regionais, pois

${ }^{3}$ O ensino em Minas Gerais no tempo da República. Belo Horizonte: Centro Regional de Pesquisas Educacionais de Minas Gerais, 1962, p. 19. 
a modernização [mineira] teve uma trajetória complexa e multifacetada. Por diversos fatores a modernidade não se implantou por inteiro nem de uma só vez. Talvez o principal seja que os ideais de modernidade difundidos no estado estiveram misturados a elementos de uma sociedade tradicional, cuja população era expressivamente rural, cuja economia apoiava-se na produção agrária voltada a um mercado interno e cujo poder político era oligárquico ${ }^{4}$.

Os constituintes mineiros, contudo, perceberam a instrução como uma missão maior e a inscreveram de forma incisiva na Constituição estadual (também de 1891), seguindo-se legislações complementares que regulamentavam a oferta desse direito a todos os mineiros: em 1892 saiu a lei n. $41^{5}$ e em 1893 o Decreto n. 655 . Dessa forma, apesar de uma demora de 3 anos após o início da República, percebe-se no estado um cuidado particular pela busca de alternativas no campo da educação que pudessem alavancar o progresso em seu território ou, pelo menos, reverter o quadro de profundo analfabetismo de sua população. Por outro lado, a exigência da alfabetização para a participação política tornava a difusão da instrução primária um imperativo. Nas palavras de Rosa Fátima de Souza, no amplo projeto civilizador republicano, "a educação foi atrelada à cidadania e, dessa forma, foi instituída sua imprescindibilidade para a formação do cidadão"7. Além disso, responsabilizada pela formação cívica da população, a educação desempenharia também funções complementares de controle social e manutenção da ordem.

E para se conseguir bons resultados no ensino primário, objetivo primeiro do estado, seria preciso mais do que a simples criação de escolas e contratação de professores. Seriam necessários recursos financeiros, escolas de formação de professores, estrutura de inspeção, material didático, conscientização dos pais e métodos eficazes, entre outros mecanismos, para a formação de um sistema de ensino.

Apesar de reconhecermos que a importância de cada um desses elementos não pode ser aquilatada em separado e o conjunto depende das partes, pretendemos nos concentrar sobre a questão do método e, mais especificamente, sobre determinado método que foi criado por um intelectual mineiro na década de 1890 e que foi amplamente distribuído entre as escolas do estado. Este enfoque específico não diminui a importância do estudo, pelo contrário, pois como nos diz Maria do Rosário Longo Mortatti,

Em nosso país, a história da alfabetização tem sua face mais visível na história dos métodos de alfabetização, em torno dos quais, especialmente desde o final do século XIX, vêm-se gerando tensas disputas relacionadas com "antigas" e "novas" explicações para um mesmo problema: a dificuldade de nossas crianças em aprender a ler e a escrever, especialmente na escola pública ${ }^{8}$.

\footnotetext{
${ }^{4}$ CARVALHO, Luciana Beatriz de Oliveira Bar de; CARVALHO, Carlos Henrique de. O lugar da educação na modernidade luso-brasileira no fim do século XIX e início do XX. Campinas: Alínea, 2012, p. 98.

${ }^{5}$ MINAS GERAIS. Lei n. 41 - Dá nova organização á instrucção publica do estado de Minas. Colecção das leis e decretos do estado de Minas Geraes em 1892. Ouro Preto: Imprensa Official de Minas Geraes, 1893.

${ }^{6}$ MINAS GERAIS. Decreto n. 655 - Promulga o regulamento das escolas e instrucção primaria. Colecção das leis e decretos do estado de Minas Geraes em 1893. Ouro Preto: Imprensa Official de Minas Geraes, 1894.

${ }^{7}$ Templos de civilização: a implantação da escola primária graduada no Estado de São Paulo (1890-1910). São Paulo: UNESP, 1998, p. 26-27.

${ }^{8}$ História dos métodos de alfabetização no Brasil. In: Seminário Alfabetização e Letramento em Debate. Brasília: MEC/SEB, 2006, p. 1.
} 
Nesse sentido, vamos nos deter na análise sobre o surgimento e a difusão do Methodo Penido, desenvolvido pelo Prof. Agostinho Maximo Nogueira Penido, de Ouro Preto, no ano de 1890, tentando recuperar um pouco da trajetória desse personagem e de seu método nas terras mineiras. Ao mesmo tempo, procuraremos avançar na compreensão das relações entre estado e municípios no esforço comum pela educação popular, observando como a apresentação e difusão do método em análise repercutiu tanto no âmbito local como estadual. E como ambas as esferas estimulam ou se se integram no esforço da sua divulgação.

\section{Agostinho Penido}

Antes de tratarmos do método, consideramos oportuno contextualizar minimamente o período e a formação do autor, bem como sua trajetória profissional e relações sócio-políticas. Apesar de não muito escassas, são dispersas as informações sobre o personagem. A documentação trabalhada nos permite identifica-lo como um bacharel, com passagens pelo Colégio do Caraça e pela Faculdade de Direito de Recife, juiz e promotor em cidades do estado, professor na cidade de Ouro Preto, onde também exerceu atividades empresariais e foi membro da Intendência nomeada pelo governo de Minas Gerais em 1890. Os registros ainda o localizam em Belo Horizonte nas primeiras décadas do século XX, onde também atuou no campo do jornalismo. Mas não podemos avançar muito mais do que isso, como tentaremos demonstrar a seguir.

Não conseguimos identificar elementos básicos de sua biografia, como data de nascimento e morte, estudos iniciais, período completo em que exerceu a docência, etc. No entanto, certos registros localizados - e que poderão servir de base para futuras incursões em busca do seu itinerário - nos permitem compreender boa parte do percurso empreendido por Agostinho Penido e contextualizar a preocupação que nos move em torno do método de alfabetização desenvolvido pelo mesmo.

Consultando o livro de matrículas de 1860, do Colégio do Caraça, encontramos a anotação de número 278 , referente à sua entrada nesse estabelecimento em outubro de 1860 , informando-se a seguir que por lá permaneceu até 31 de janeiro de 1862. A matrícula 277 refere-se a seu irmão Antonio Maximo Nogueira Penido, onde se encontra o nome do pai de ambos: Dr. Jeronymo Maximo Nogueira Penido e a indicação da proveniência de Ouro Preto. Uma anotação complementar o coloca como "professor em B. Horz.te [Belo Horizonte]"9. Estes dados, para além de demonstrarem que nosso personagem teve acesso a um dos mais respeitados colégios secundários do País no século XIX, nos permitem presumir também que seu nascimento provavelmente tenha se dado nos anos iniciais da década de 1840. Mesmo porque, o casamento de seus pais ocorreu em 29 de julho de $1839^{10}$.

Embora não tenhamos como delimitar como transcorreu todo seu período de estudos secundários, para além desse pouco mais de um ano no Colégio do Caraça, conseguimos identificar, na sequência de sua formação, um registro que comprova o título de bacharel que sempre ostentou em sua apresentação, tendo sua formatura em ciências "Juridicas e Sociaes" ocorrido na Faculdade de Direito de Recife, em $1872^{11}$.

9 COLÉGIO do Caraça. Livro de Matrícula 1860. Disponível em: http://www.santuariodocaraca.com.br/ livro-de-matricula-1856-1910/livro-de-matricula-1860/. Cf. também: COLÉGIO do Caraça. Lista de Ex-alunos. Disponível em: http://www.santuariodocaraca.com.br/lista-de-ex-alunos/lista-de-ex-alunos-letra-a/. Consulta em 07/05/2015.

10 PENIDO, Jeronimo Maximo Nogueira. Base de dados de todos os parentes, colaterais e não parentes. Disponível em: http://www.geocities.ws/basededadoscastro/pafg56.html, consulta em 07/05/2015.

11 MARTINS, Henrique. Lista geral dos bachareis e doutores que têm obtido o respectivo gráo na Faculdade de Direito do Recife, desde sua fundação em Olinda no ano de 1828, até o ano de 1931. Recife: Typographia Diario da Manhã, 1931, p. 11. Disponível em https:/www.ufpe.br/ccj/images/bachareis/ bacharis\%201828\%20-\%201931.pdf, consulta em 07/05/2015. Cf. 
Em 1873, no Relatório apresentado à Assembléia Legislativa Provincial, pelo então Presidente da Província de Minas Gerais, Venancio José de Oliveira Lisbôa, encontramos menção a uma das atividades que teriam sido desenvolvidas por Agostinho Penido. Nesse documento, lê-se: "Do $1^{\circ}$ de Março até hoje forão por mim nomeados Promotores Publicos: Major Manoel José Ferreira Bretas para a comarca de Cabo Verde. (...) Bacharel Agostinho Maximo Nogueira Penido para a do Rio das Mortes". Esse Relatório nos permite acompanhar sua movimentação por cidades do estado, mas não ter a certeza de que tenha realmente exercido a função, pois ao final acrescenta-se: "Não entrarão ainda em exercício os das [comarcas] do Paranahyba, Rio das Mortes, Murihaé, Jacuhy, Prata, Cabo Verde, Itajubá, Itapirassaba"12.

No ano seguinte, em informe na "Parte Official", sobre o Ministério da Justiça, o Diário de Pernambuco acrescenta mais um dado sobre a circulação de Agostinho Penido pela província: "Por decretos de 7 de agosto do corrente: (...) Foram nomeados: (...) o bacharel Agostinho Maximo Nogueira Penido juiz municipal e de orphãos do termo de Lavras, na provincia de Minas-Geraes"13. Em 1888, no jornal A Provincia de Minas, "Orgão do Partido Conservador", de 10 de fevereiro de 1888, encontramos indicação de nova nomeação: "Para os cargos de suplentes do juiz municipal, nos districtos especiaes, nos diversos termos da província, no quatriênio que começa a 22 de março vindouro, forão nomeados: (...) Bomfim. (...) $3^{\circ}$ Agostinho Nogueira Penido" ${ }^{14}$. Por essas menções, podemos perceber que Agostinho Penido iniciou sua carreira como funcionário público no campo da justiça logo após sua formatura, como promotor e como juiz, embora ao que parece não tenha se concentrado apenas na mesma pelos dados que compilamos sobre os anos seguintes.

Outro documento nos mostra que em 1876 Agostinho Penido embrenhou-se também pelas artes da política, pois na listagem dos deputados e senadores de Minas Gerais, do período imperial, encontramos o nome do nosso personagem como deputado provincial nos anos de 1876-1877. Nesse mesmo documento somos informados que seu pai, Jeronymo Maximo Nogueira Penido, teria também se dedicado às lides políticas entre 1840 e $1863^{15}$.

Apesar dessas ligações da família e do próprio Agostinho Penido com o mundo da política, localizamos outros registros relacionados a atividades empresariais, alguns anos à frente. O Decreto n. 8248, de 3 de setembro de 1881, do Governo Imperial, informa que

Attendendo ao que Me requereram os Bachareis Jeronymo Maximo Nogueira Penido Junior e Agostinho Maximo Nogueira Penido, Hei por bem Conceder-lhes permissão para explorarem ouro no arraial de Congonhas de Campos, termo de Ouro Preto, na Provincia de Minas Geraes $^{16}$.

\footnotetext{
12 LISBÔA, Venacio José de Oliveira. Relatório que á Assemblea Legislativa Provincial de Minas Geraes apresentou na sessão ordinária de 1873 o Presidente da Provincia. Disponível em: http://brazil.crl.edu/bsd/bsd/480/000008.html, consulta em 07/05/2015.

13 PARTE Official. Diario de Pernambuco, anno L, n. 18, 23 de janeiro de 1874, p. 1. Disponível em http://ufdc.ufl.edu/AA00011611/17555/1x?vo=3, consulta em 07/05/2015.

${ }^{14}$ SUPLLENTES do Juiz Municipal. A Provincia de Minas, Anno VIII, n. 513, 10 de fevereiro de 1888, p. 2. Disponível em: http://memoria.bn.br/DocReader/Hotpage/HotpageBN.aspx ?bib=222747\&pagfis=1314\&url= http://memoria.bn.br/docreader\# (consulta em 18/01/2018).

${ }^{15}$ HISTÓRIA das Minas de Ouro e Diamante: a Lista dos 120 Ex-Alunos do Caraça na Política. Disponível em: http://monlewood.blogspot.com.br/2015/02/historia-das-minas-de-ouro-e-diamante.html, consulta em 07/05/2015.

${ }^{16}$ BRASIL. Decreto n. 8248, de 3 de setembro de 1881. Disponível em: http://legis.senado.gov.br/legislacao/ ListaTextoIntegral.action?id=57457\&norma=73310, consulta em 07/05/2015.
} 
Nesse ramo, nosso autor parece ter perseverado por mais tempo, já que após a proclamação da República vamos encontrá-lo buscando a continuidade desse privilégio, agora sem a companhia de seu irmão. O Decreto 609/1890, de 31 de julho de 1890, do Governo Provisório do Marechal Deodoro da Fonseca, "Concede permissão ao Bacharel Agostinho Maximo Nogueira Penido para explorar ouro e outros minerais no estado de Minas Gerais"17.

Ainda no campo empresarial, encontramos menção em 1887 a outra iniciativa de Agostinho Penido, agora no ramo urbanístico de Ouro Preto, então capital do estado de Minas Gerais. André Luiz Mantovani, utilizando-se de relatórios de presidentes da Província, nos diz que em "01 de outubro de 1887 foi concedido ao bacharel Agostinho Maximo Nogueira Penido privilégio para a iluminação a gás da capital"18.

Continuando pela senda da política, já no período que nos interessa mais diretamente, vamos encontrá-lo em 1891 como membro do Conselho de Intendentes da cidade de Ouro Preto, que se instala após o fechamento das Câmaras Municipais, por conta da instauração da República em 1889. Nesse espaço propõe, em 13 de junho de 1891, a criação de 4 escolas noturnas em bairros de Ouro Preto, indicando em 3 de setembro desse mesmo ano "para que desde já seja creada uma secção de instrucção publica, composta de um dos officiaes da Secretaria e dous amanuenses"19, etc. E também observações em relação ao método de alfabetização que criara no ano anterior, como veremos mais à frente.

Finalmente, para os limites temporais que estabelecemos para o presente estudo, devemos registrar que nosso personagem inicia sua atuação como professor em 1891, conforme correspondência que envia ao Presidente da Intendência Municipal de Ouro Preto em 22 de agosto de 1891, respondendo ofício recebido dessa mesma Intendência, em que informa exercer "o magisterio desde 17 de Fevereiro do corrente anno e nomeado pelo gov. posteriormente aquella dacta, prossegui no mesmo exercicio e sem interrompel-o jamais" 20 .

Embora exceda nosso recorte, seria interessante anotar que Agostinho Penido também voltou-se para o jornalismo, embora não tenhamos conseguido identificar os anos precisos dessa atividade. Pedro Nava, em suas memórias relativas ao período em que sua família mudou-se para Belo Horizonte, provavelmente entre 1913-1916, informa ter sido vizinho do nosso personagem: "O tal Dr. Penido era um belo velho de perfil judaico e cãs esvoaçantes que lhe davam ar de profeta no ato de. Andava sempre de sobrecasaca e cartola, era extremamente pomposo nos modos e nas suas falas". Além dessas características, acrescenta:

Conhecia outras coisas e era bom professor, bom jornalista. Publicava a Vanguarda, órgão oficial de seus interesses pessoais, no início folha diária, depois semanal, quinzenal, mensal, bimestral, semestral, anual, bissexta, finalmente episódica e só dando número no dia em que o nosso Dr. Penido tinha qualquer coisa para resolver ou quando queria agradar o Presidente do Estado, os Senhores Secretários ou os Nobres Deputados $^{21}$.

17 BRASIL. Decreto $\mathrm{n}^{\mathrm{o}}$ 609, de 31 de Julho de 1890. Disponível em: http://www2.camara.leg.br/legin/ fed/decret/1824-1899/decreto-609-31-julho-1890-523693-publicacaooriginal-1-pe.html. Consulta em 07 mai. 2015.

18 MANTOVANI, André Luiz. Faça-se a luz: modernidade e demandas sociais na eletrificação da iluminação pública de Ouro Preto, 1880-1920. Mariana: UFOP, 2005, p. 37 (monografia de bacharelado).

${ }^{19}$ CÂMARA Municipal de Ouro Preto. Livro de Registro de Atas (resoluções) da Intendência Municipal - 18901894. Ouro Preto: Arquivo Municipal de Ouro Preto, Livro n. 894.

${ }^{20}$ CÂMARA Municipal de Ouro Preto Caixa Instrução. Ouro Preto: Arquivo Municipal de Ouro Preto (vários anos).

${ }^{21}$ NAVA, Pedro. Balão Cativo: memórias/2. Rio de Janeiro: J. Olympio, 1977, p. 99-100. 
Por esse conjunto de informações, pode-se perceber que Agostinho Penido foi um intelectual de múltiplas faces, tendo usufruído de educação primorosa e gozado de prestígio sócio-político no período imperial, que se estende pelo menos aos anos iniciais da República. Fez incursões por diversos campos, política, mineração, magistratura, promotoria, jornalismo, autoria de livro didático e pela docência. Daí a riqueza do personagem, ainda que os dados que tenhamos conseguido sobre o mesmo sejam um tanto imprecisos. Mas, acreditamos, suficientes para delinear seu perfil e estimular à continuidade de pesquisas sobre o mesmo.

\section{O surgimento do Método}

Não foi possível encontrar referências que nos permitissem compreender as razões porque um advogado, envolvido com a política e com a iniciativa privada resolveu enveredar pelo campo da educação e, mais especificamente, pela produção de livro didático voltado para a alfabetização. Talvez seu envolvimento com os problemas dos municípios onde atuou e as discussões políticas em que tenha se envolvido o tenham sensibilizado para a busca de alternativa para a superação dos graves problemas do analfabetismo e do aprendizado da leitura, como coloca em diversas correspondências, em que destaca seu particular apreço pela educação. Pelo que pudemos constatar, o histórico sobre o método de alfabetização desenvolvido por Agostinho Penido inicia-se, pela documentação localizada no Arquivo Público Mineiro, por uma correspondência do autor, de 12 de fevereiro de 1890, apresentando sua proposta para aproveitamento por parte das autoridades do estado:

Diz respeitosamente o Bel. Agostinho Penido, que tendo inventado um novo methodo de leitura que facilita extraordinariamente o ensino primário, pede a V. Exa. digne-se nomear uma commissão que, assistindo a uma experiência feita pelo supplicante, com analphabetos por elle leccionados apenas alguns dias, ou por outros da escolha da commissão, dê parecer sobre a sua approvação e adopção ${ }^{22}$.

O despacho do então governador em exercício, João Pinheiro, foi positivo, mas lacônico: "Á Inspectoria Geral da Instrucção Publica, para providencias". Ao lado, o Inspetor Geral, Affonso Brito, acrescentou os nomes dos professores nomeados para compor comissão avaliadora do dito método, estabelecendo o dia 15 de fevereiro para a reunião e indicando o local e hora.

No mesmo processo, com data de 14 de fevereiro de 1890, encontramos outro documento, assinado pelo Padre Candido Ferreira Vellozo, "professor de Instrucção primaria e religiosa e Capellão da Cadêa d'esta Capital", dando seu testemunho sobre os benefícios do método de alfabetização:

Attesta que, o Ilmo. Snr. Dr. Agostinho Penido no interesse de facilitar com promptidão aos analphabetos um methodo claro para aprenderem a ler, conseguio o seo desideratum, e com tanta vantagem que, fazendo uma experiencia na escola da Cadêa d'esta Capital com quatro alumnos completamente analphabetos, obteve que os ditos alumnos no espaço de vinte e cinco minutos pudessem sem esforço conhecer as lettras, as syllabas e sem obstáculo lerem as duas lições apresentadas. Esta experiência foi feita á minha presença e posso

\footnotetext{
${ }^{22}$ MINAS GERAIS. Secretaria do Interior. Fundo Instrução Pública, n. SG1052, 1890. Arquivo Público Mineiro. As informações seguintes, sobre o surgimento do Methodo Penido, provêem desse mesmo conjunto documental.
} 
affirmar que o dito methodo vem trazer uma verdadeira vantagem ao ensino primário arredando tantas difficuldades e plantando logo o gosto nos alumnos.

Com o método em mãos e esse testemunho, a comissão, composta pelos professores Camillo de Brito, Maria Fiusa de Oliveira e Cherubina Rodrigues Pombo de Miranda, dedicou-se à sua avaliação e no mesmo dia 15 de fevereiro encaminhou o parecer para $\mathrm{o}$ Conselho Litherario, nos seguintes termos:

Nomeados para emittir o nosso parecer sobre o Methodo de leitura immediata pelo Dr. Agostinho Penido, depois de assistir a pratica de ensino feita a uma creança de tres annos e a adultos analphabetos podemos afirmar que o processo empregado é de vantagem intuitiva.

Entre os methodos empregados até hoje nenhum é considerado incompleto ou defeituoso, mas alguns são poucos amenos e outros exigem applicação demorada. Este de leitura immediata attinge ao seu fim por meio do conhecimento gradual das lettras e das syllabas, em 58 lições e ligeiros exercicios; ao mesmo tempo os alumnos reproduzem no quadro negro as lições, chegando a escrever o que lerão sem nova aprendizagem. É a modificação dos dous processos phonetico e de soletração, de adopção muito aproveitavel nas escolas; os meninos facilmente o comprehendem por ser simples e racional a formação das lettras, das syllabas e das palavras. Entre os systhemas em grande numero publicados nenhum excede no mechanismo e na adaptação á intuição dos meninos ao da leitura immediata.

O Conselho Litherario, por sua vez, procederá à sua análise no dia 20 de fevereiro de 1890, emitindo igualmente parecer favorável. Deve-se anotar, contudo, que foram registrados 3 votos vencidos entre os 8 membros do conselho. Apesar de ser considerado "util e portanto no caso de ser adoptado nas Escolas primarias", o método não alcançou a unanimidade.

A caracterização feita pela comissão avaliadora sobre o tipo de método apresentado, mostrando tanto o avanço do Methodo Penido como suas variações sobre os métodos em uso naquela época e, ainda, as discussões ocorridas no Conselho Litherario nos mostram que a questão do método, como já adiantamos, era um dos aspectos considerados centrais no final do século XIX. Pode ser que Agostinho Penido tenha percebido a importância dessas questões e resolvido participar da "querela" dos métodos, como tem sido denominada essa questão no interior da historiografia ${ }^{23}$. Apesar de não termos encontrado nenhum exemplar do Methodo, que pudesse servir de material para análise mais precisa sobre a forma como foi pensado e construído para promover a alfabetização, localizamos, mais uma vez em Pedro $\mathrm{Nava}^{24}$, uma descrição resumida sobre sua forma de aplicação:

Como professor, tinha um processo seguro de ensinar o alfabeto, estimulando a memória dos meninos com uma associação figurativa ou homofônica para cada letra. Meu irmão Paulo [1908-1998], que aprendeu a ler com ele, lembrava-me há tempos algumas. B, por

\footnotetext{
23 Maria do Rosário Longo Mortatti nos apresenta uma síntese dessa discussão e uma periodização interessante sobre o andamento do debate sobre métodos de alfabetização no Brasil em "A 'querela dos métodos' de alfabetização no Brasil: contribuições para metodizar o debate". Revista ACOALFAplp: Acolhendo a Alfabetização nos Países de Língua portuguesa, ano 3, n. 5, 2008, p. 91-114.

${ }^{24}$ Op. cit., p. 100.
} 
exemplo, fixava-se no bestunto com a frase - Bezerro torce o pé. $C$ era Cabrito sobe a serra. G, Goiaba fruta gostosa; $M$, Melado é bom doce; U, Uva boa e açucarada; V, Veado tem galho; X, Xico trança as pernas; Z, Zebra arisca riscada...

Continuando os trâmites burocráticos referentes à publicação do método aprovado na comissão e no conselho, em 21 de fevereiro de 1890, o Inspetor Geral da Instrucção Publica, Affonso Luiz Maria de Britto, encaminha ofício ao Governador do estado, informando:

Em cumprimento do vosso despacho de 12 do corrente mez, submetti ao exame de uma commissão de professores primários e posteriormente ao Conselho Litterario o Methodo de Leitura Immediata do Dr. Agostinho Penido. Pelos pareceres juntos vereis que o Methodo foi considerado útil e no caso de ser adoptado nas Escolas primarias. Esta Inspectoria julga que os pareceres forão bem fundamentados e que o autor do Methodo prestou relevante serviço á Instrucção Publica.

Em 27 de fevereiro de 1890 a Intendência Municipal de Ouro Preto, demonstrando que o interesse pelos avanços da instrução estava entranhado nas preocupações municipais, também se manifesta sobre o auspicioso método que acabara de ser criado:

A Intendência Municipal da Capital do Estado de Minas Geraes espontaneamente firma em sua conferencia de hoje 27 de Fevereiro de 1890 um voto de louvor ao Illustre Cidadão Dr. Agostinho Maximo Nogueira Penido pelo methodo de leitura de sua invenção, por meio do qual conseguio fazer com que quatro analphabetos, com poucas lições, em sua presença conseguissem conhecer as letras, formar sylabas, soletrar e ler phrazes pelo mesmo Dr. escriptas, e em vista de tal resultado aplaude e louva ao inventor de tão aproveitante methodo de ensino.

A experiência com os citados analfabetos, que ocorrera nesse mesmo dia, com a participação de quatro detentos da cadeia de Ouro Preto, já mencionados na correspondência do Padre Cândido Velozo, parece ter realmente chamado a atenção da sociedade ouro-pretana, pois foi também registrada por documento dessa mesma data, assinado pelo carcereiro Jose Simplicio Guimarães:

Remetto-vos em virtude de ordem do Sr. Dr. Chefe de Policia, para uma experiência perante a intendência municipal os presos Innocencio dos Santos Queiroz, Isidro Pereira dos Santos, Luis e Silverio, que hão sido por vos leccionados durante duas horas apenas, sendo meio hora frente o professor d'esta Cadea, meia hora perante o Governador do Estado, que se dignara também assistir a vossa experiência e mais uma hora em dias subseqüentes.

Após essa sequência de procedimentos, com o aval da comissão avaliadora, do Conselho Litherario, o testemunho do capelão e professor da cadeia, do carcereiro e o voto de louvor da Intendência Municipal, o governador em exercício, João Pinheiro da Silva, toma sua decisão sobre o método, em 11 de março de 1890: 
O Dr. Vice-Governador do Estado de Minas Geraes, tendo em vista a informação da Inspectoria Geral da Instrucção Publica N. 439 de 21 de Fevereiro findo, a que acompanharam os pareceres prestados por uma comissão de três professores, nomeada pela mesma Inspectoria, e pelo Conselho Director, nos quaes se afirma que o methodo de leitura immediata do Dr. Agostinho Penido attinge ao seu fim por meio do conhecimento gradual das lettras e das sylabas em 58 lições e ligeiros exercícios, sendo por isso considerado util; resolvo que seja o referido methodo adoptado nas escolas publicas deste Estado.

Esta aprovação da publicação e adoção do Methodo por parte do governo do estado não deve ser considerada atípica ou em benefício de algum apaniguado político, não apenas por conta de todos os rituais avaliativos por que passou mas também porque a publicação de livros didáticos produzidos por professores não era um fenômeno desconhecido no universo educacional brasileiro do final do século XIX. O envolvimento dos docentes com o processo de avaliação ou geração de compêndios escolares, como o que envolveu o Methodo Penido, tinha suas raízes ainda no período imperial, como nos dizem Alessandra Frota M. de Schueler e Giselle Baptista Teixeira, discutindo um livro escolar de 1883:

No percurso que envolvia os livros escolares, mais do que consumidores passivos destes objetos auxiliares de suas aulas, os professores tornaram-se sujeitos ativos, seja analisando e avaliando as obras que deveriam ser autorizadas para uso das escolas, a pedido do Governo, seja produzindo tais compêndios. Professores primários e secundários passaram a elaborar livros e materiais didáticos, tornandose assim autores de obras destinadas ao ensino nas escolas primárias e secundárias ${ }^{25}$.

E a prática acabou sendo aprimorada em Minas Gerais, com a inclusão de estímulos específicos para esse tipo de trabalho na legislação que se foi estabelecendo nos anos posteriores à aprovação do Methodo Penido pelo governo. Na citada lei n. 41, de 1892, encontraremos orientações precisas sobre a realização de concursos e oferta de prêmios para autores de livros didáticos "sobre todas as matérias lecionadas nas escolas urbanas", bem como sobre a distribuição dos mesmos pelas escolas públicas do estado:

Art. 327 - O governo estabelecerá e anunciará prêmios a autores de trabalhos didáticos que em concurso forem adotados para compêndio das escolas primárias e que se tornarão propriedade do Estado. O julgamento do concurso caberá ao conselho superior da instrução pública, observados os preceitos e formalidades que forem estabelecidos em regulamento especial, a fim de assegurarem a mais escrupulosa justiça nas decisões. (...) Art. 328 - Adotados definitivamente os compêndios a que se refere o artigo anterior, o governo mandará imprimi-los dentro ou fora do país, em edições estereotipadas nunca inferiores a cinquenta mil exemplares cada uma, reservados os clichés para subsequentes tiragens. (...) $\mathrm{O}$ respetivo professor [que receberá os livros], responsável por esse

\footnotetext{
${ }^{25}$ Civilizar a infância: moral em lições no livro escolar de Guilhermina de Azambuja Neves (Corte imperial, 1883). Revista de Educação Pública, v. 17, n. 35, set-dez 2008, p. 564.
} 
depósito, com assistência do inspetor ou do conselho de inspeção local, fará distribuição gratuita dos compêndios no começo do ano letivo aos alunos reconhecidamente pobres e que como tais figurem na matrícula. Aos que não forem pobres e quaisquer outras pessoas, os compêndios serão vendidos pelos preços que o governo previamente fixar.

Por essas prescrições, que serão retomadas nos artigos 186 a 189 do decreto n. 655, de 1893, que regulamentou o ensino no estado, vemos que Minas Gerais institucionalizou a realização de concursos com procedimentos semelhantes aos que foram praticados no processo de avaliação do trabalho do professor Agostinho Penido. Pode-se supor, inclusive, que talvez o seu processo tenha servido como "modelo" aos dispositivos que foram colocados posteriormente na lei.

\section{A difusão do Método}

Embora não tenhamos encontrado indicação do número exato de livros que foi publicado, pelo que consta na documentação trabalhada milhares de exemplares do Methodo Penido foram disponibilizados nos anos seguintes e largamente distribuídos pelas escolas do estado. Várias solicitações presentes na correspondência da Secretaria do Interior explicitam que seu uso foi efetivo e que deve ter tido boa aceitação entre os professores. No entanto, dada a carência generalizada de livros didáticos no período analisado, essas solicitações não garantem um reconhecimento pela qualidade do material. Mas indicam que o método teve repercussões nos educandários mineiros.

Trataremos inicialmente da circulação da obra no município de Ouro Preto, a partir de documentação da Câmara local. Nas atas da Intendência Municipal de Ouro Preto, de cujo conselho fazia parte Agostinho Penido em 1891, iremos encontrar algumas menções referentes à utilização do Methodo Penido nas escolas da capital e em seu entorno, bem como do interesse do autor para o uso alargado de sua proposta de alfabetização. Na sessão do dia 10 de outubro de 1891 está registrado:

Foi lido um officio do secretario, fazendo ver que diversos cidadãos de fóra deste município têm requisitado livros do methodo Agostinho Penido - e como não possa satisfazer-se sem ordem, traz o facto ao conhecimento da Intendencia para resolver. Tomando a palavra o Intendente Dr. Penido, faz ver que de boa vontade e em bem da Instrucção publica que tanto precisa de protecção, offerece gratuitamente os exemplares necessarios afim de serem distribuidos, o que a Intendencia acceitou, ordenando que nesta acta se lavrasse um protesto de agradecimento ao mesmo Dr. Penido para sempre constar ${ }^{26}$.

No ano seguinte, em $1^{\circ}$ de outubro de 1892, extinta a Intendência - da qual Agostinho Penido se afastara por renúncia no início desse ano - e com vereadores empossados desde março, encontraremos mais uma vez nosso personagem citado nas sessões da Câmara Municipal, agora para fazer solicitação de financiamento para produzir uma nova edição de seu método, no qual declara haver feito aprimoramentos:

${ }^{26}$ CÂMARA Municipal de Ouro Preto. Livro de Registro de Atas (resoluções) da Intendência Municipal-18901894. Ouro Preto: Arquivo Municipal de Ouro Preto, Livro n. 894. 
Achão-se sobre a mesa e são expostos á consideração da Camara os seguintes papeis. Uma representação do Dr. Agostinho Maximo Nogueira Penido, cedendo gratuitamente para as escolas do municipio seis mil exemplares de seu methodo de ensino que diz haverem sido entregues a administração transacta, e solicitando, por uma só vez, o auxilio da quantia de dez contos de reis para reimprimir a mesma obra depois de aperfeiçoada, obrigando-se a ministrar mais dez mil exemplares, e a fazer no municipio o ensino deste novo methodo durante o periodo das ferias escholares. - Á commissão interna ${ }^{27}$.

Por registros encontrados nos trabalhos camarários desse mesmo ano podemos confirmar que os livros foram realmente distribuídos pelas escolas do município e que Agostinho Penido estava nesse momento buscando recursos para uma segunda edição, segundo ele, revista e mais modernizada. Em outro conjunto documental encontramos o texto da referida representação enviada aos vereadores, embora estranhamente com data posterior ao registro acima, do dia 10 de outubro de 1892:

Exmo. Snr. Dr. Presidente e mais dignos representantes do município. Só a virtude tem valor real. É ancora no oceano da vida. Pharol na immensidade dos ceos! Sabeis dos esforços do suplicante pela causa da instrucção. Sabeis que na lucta elle tem esquecido de si e dos seos para só lembrar-se da Patria. Pois bem, por tudo isto ponderando que já cedeo para a Camara seis mil exemplares de seo Methodo e que hão sido livremente distribuidos e com os melhores resultados como tem proclamado a imprensa, tem a honra de propor. O suplicante nada receberá dos cofres municipaes pelos livros de sua sagrada propriedade e que pela mesma Câmara hão sido distribuidos pelas escolas. Em justíssima compensação, porem, pela mais legitima equidade, a Camara auxiliará o suplicante com a quantia de dez contos, pagos de uma só vez para os seguintes fins: $1^{\circ}$. Publicar o seo ultimo e aperfeiçoado systema de ensino. $2^{\circ}$ Stereotipar a publicacão de modo a tirar grandes edicões dando o suplicante dez mil exemplares á Camara para esta distribuir pelo municipio. $3^{\circ}$ Obrigar-se o suplicante no periodo das ferias escolares á fazer o ensino de seo methodo por todo o municipio. Para base de tudo expoz o suplicante o seo Methodo ainda em provas e apellando para o vosso patriotismo espera a devida Justiça ${ }^{28}$.

A solicitação tem o despacho "À comissão interna" e não se sabe se o município atendeu à solicitação do professor Penido. No entanto, pelo conteúdo de ofício da Câmara Municipal enviado ao Presidente do estado, em 12 de agosto de 1892, podemos perceber a disposição do município para a publicação de livros didáticos para suas escolas, em retribuição à ação estadual de prover Ouro Preto com escolas sob sua responsabilidade, dispensando a Câmara desses gastos. Pode ser, inclusive, que, por conta dessa informação, nosso personagem tenha apresentado a solicitação acima, ou que contatos do mesmo com as autoridades municipais tenham estimulado a disposição editorial da Câmara. Nesse ofício, argumenta-se:

\footnotetext{
${ }^{27}$ Idem.

${ }^{28}$ CÂMARA Municipal de Ouro Preto. Caixa 1892. Ouro Preto: Arquivo Municipal de Ouro Preto. O resumo dessa correspondência encontra-se registrado nas atas da Câmara, no dia $1^{\circ}$ de outubro de 1892: CÂMARA Municipal de Ouro Preto. Livro de Registro de Atas (resoluções) da Intendência Municipal - 1890-1894. Ouro Preto: Arquivo Municipal de Ouro Preto, Livro n. 894.
} 
De todos os pontos deste Municipio reclama-se o fornecimento de livros para o ensino primário, e de muitos outros municipios tenho recebido pedidos para ceder-lhes os que acaso esta Camara houvesse disponíveis. De testemunho pessoal sei que em algumas escolas as creanças estam lendo jornaes e outros impressos que nem sempre nutrem de boas idéas, e affectos limpos a primeira idade. Nestas circunstancias a Camara deseja mandar emprimir os livros de leitura necessários a serem offerecidos ás Escolas Estadoaes do Municipio, visto como felizmente o Estado tem creado e mantido o numero d'ellas sufficiente, dispensando-nos assim do encargo de estabelecer novas $^{29}$.

Apesar dessa disposição camarária, o andamento da discussão não permite saber com certeza se essas intenções de publicação se concretizaram, principalmente porque, durante esses anos iniciais da República, a Câmara sempre esteve às voltas com problemas financeiros, relatados em suas atas. De qualquer forma, essas passagens expondo o empenho do autor, ao lado da disposição/relutância de estado e município, nos permitem ampliar um pouco mais um outro campo de embates no final do século XIX, relacionado às relações entre autores e editores, notadamente daqueles que produziam livros voltados para o ensino, marcadas por tensões, conflitos, acordos, discriminações, etc, nem sempre perceptíveis pelo público. Circe Maria Fernandes Bittencourt ${ }^{30}$, analisando essa questão no século XIX e início do século XX, chama a atenção para a complexidade dessas relações:

O autor de uma obra didática deve ser, em princípio, um seguidor dos programas oficiais propostos pela política educacional. Mas, além da vinculação aos ditames oficiais, o autor é dependente do editor, do fabricante do seu texto, dependência que ocorre em vários momentos, iniciando pela aceitação da obra para publicação e em todo o processo de transformação do seu manuscrito em objeto de leitura, um material didático a ser posto no mercado.

Os resultados apresentados por Circe Bittencourt, bem como os esforços despendidos por Agostinho Penido, nos permitem perceber que não era fácil a vida de autores de livros didáticos no período que nos ocupa. Tanto para conseguir a publicação do material gerado como para auferir algum lucro, ou mesmo reconhecimento, por meio do seu texto. Essa labuta incessante pode ser visualizada, mais à frente, quando encontramos uma mudança de estratégia - quase desesperada - do mesmo Agostinho Penido em sua busca de recursos para sua sobrevivência associada à disseminação do Methodo, agora com nova solicitação, tentando receber algum numerário pelos livros anteriormente doados às escolas municipais, alegando estar passando por dificuldades financeiras e com problemas de saúde. Em 20 de outubro de 1894, o presidente da Câmara convoca os vereadores para discutir vários assuntos pendentes, entre eles,

\footnotetext{
${ }^{29}$ MINAS GERAIS. Secretaria do Interior. Fundo Instrução Pública, n. 723, 1892-1897. Arquivo Público Mineiro.

${ }^{30}$ Autores e editores de compêndios e livros de leitura (1810-1910). Educação e Pesquisa, v. 30, n. 3, set./dez. 2004, p. 479.
} 
Hum recurso do Dr. Agostinho Penido. À intendência de que faria parte a 8 de Outubro de 1891 , ofertou este cidadão os livros de sua lavra que necessarios fossem ao ensino primario da mocidade; donativo que o conselho aceitou e agradeceo em nome da municipalidade digo em nome do municipio. Tres annos depois, veio reclamar os exemplares ainda restantes no paço da camara e solicitar pagamento dos já então distribuidos. Attendido na $1^{\mathrm{a}}$. Parte, não o foi na $2^{\mathrm{a}}$, por ser pretensão inteiramente descabida desde que não houve compra, mas simples aceitação de um offerecimento espontaneamente feito. O Sr. Claudionor Guites, tendo em vista a maxima utilidade dos livros distribuidos e as circumstancias difficeis do peticionario, estava disposto a indicar que apenas por equidade, se lhe desse uma retribuição podendo ser esta de $500 \$ 000$. A exigencia porem dos exemplares que depois de doados reverterão as mãos do offertante, demovera-o deste digo demovera-o desse proposito a [inclinar-se] a desatender por sua parte a reclamação, que [foi] unanimemente indeferida ${ }^{31}$.

A partir deste último fragmento, podemos presumir que as relações do professor Penido com a Câmara Municipal já não se davam de forma muito harmoniosa e que os benefícios reconhecidos ao método não eram suficientes para lhe garantir poder suficiente para fazer a edilidade aceitar suas petições.

Pelo lado das relações com o estado de Minas também ocorriam desentendimentos e observa-se uma certa desconfiança para com o trabalho desenvolvido pelo referido professor na Escola Penido, que havia sido autorizada a funcionar após o prêmio recebido, por conta da aprovação do método que levava seu nome. Com data de 18 de agosto de 1891, foi enviado ofício da Inspetoria Geral da Instrução Pública de Minas Gerais para o presidente da Intendência Municipal de Ouro Preto, nos seguintes termos: "Para a conveniente regularidade da escripturação desta Secretaria, peço-vos que me informeis qual a data em que assumio o exercicio de suas funções o professor da Escola Penido, cidadão Dr. Agostinho Penido". A resposta apresentada por Penido, já mencionada acima, foi enviada logo no dia 22 de agosto: "Exerço o magisterio desde 17 de Fevereiro do corrente anno e nomeado pelo gov. posteriormente aquella dacta, prossegui no mesmo exercicio e sem interrompel-o jamais" 32 . Sobre a criação dessa escola e nomeação do professor, numa correspondência de 26 de janeiro de 1892, enviada ao Presidente do estado pela Inspetoria Geral da Instrução Pública do Estado de Minas Gerais, informa-se que o Agostinho Penido havia anteriormente pedido exoneração do cargo de professor, bem como do cargo de membro do Conselho da Intendência da Capital, mas que agora solicitava a anulação do pedido de exoneração como professor. Concordando com a manutenção de Penido nos quadros docentes, o inspetor informa:

A referida - Escola Penido - foi creada pelo Decreto $n^{\circ} 462$ de 14 de março do anno passado e a essa creação precedeo o intuito de completando o pensamento do Governo, que mandou premiar o auctor do Methodo Penido, experimentar-se applicação do mesmo Methodo no ensino publico. Os resultados d'essa tentativa, tem sido por demais satisfatórios, devido já não somente á excellencia do Methodo

\footnotetext{
${ }^{31}$ CÂMARA Municipal de Ouro Preto. Livro de Registro de Atas (resoluções) da Intendência Municipal - 18901894. Ouro Preto: Arquivo Municipal de Ouro Preto, Livro n. 894.

32 CÂMARA Municipal de Ouro Preto Caixa Instrução. Ouro Preto: Arquivo Municipal de Ouro Preto (vários anos).
} 
empregado, como a pericia e dedicação do professor. Nestas condições, sendo concedida a exoneração pedida, a alludida - Escola - deveria ser, quando não supprimida, provida com outro professor, provindo d'ahi graves prejuizos á instrucção publica, pois que nenhum outro se encontraria, como o requerente, tão apto para a applicação do Methodo de sua invenção ${ }^{33}$.

Sobre a continuidade dessa escola, encontramos duas menções de igual conteúdo na documentação consultada, sendo uma de 3 de outubro de 1895 e outra de 29 de setembro de 1896: "O Dr. Prezidente do Estado de Minas Geraes resolve nomear o bacharel Agostinho Penido para o emprego de professor da 'Escola Penido', creada, nesta capital, pelo decreto $\mathrm{n}^{\mathbf{}}$ 426 de março de 1891" "34. Por essas informações, podemos concluir que, pelo menos até 1896, Agostinho Penido seguia como professor público, amparado por sua condição de autor do Methodo Penido na então capital do estado.

Apesar da declaração de exercício contínuo e responsável em 1891, 4 anos depois, em 14 de outubro de 1895, numa correspondência da Secretaria do Interior, com a observação "reservado" em seu início, encaminhada ao Inspetor Escolar Municipal de Ouro Preto, encontramos a seguinte orientação: "Em nome do Sr. Dr. Secretario do Interior, rogo-vos [exercer activa] fiscalização em relação a escola, regida nesta capital, pelo Sr. Agostinho Penido, pois há denuncia de que o mesmo não cumpre regularmente os seos deveres"35. Não localizamos o desfecho dessa averiguação mas a sua existência denota estremecimento nas relações com o estado, da mesma forma que ocorrera com o município, bem como a presença de indivíduos que não confiavam em seu trabalho, levando a denúncias junto aos poderes constituídos.

Ainda no tocante ao relacionamento com o estado de Minas Gerais e no incansável esforço de um autor para fazer circular seu livro, bem como daí tirar algum resultado financeiro, iremos encontra-lo tentando comercializar seus exemplares do Methodo Penido logo após a publicação do primeiro lote de exemplares. Em correspondência de 5 de março de 1891, enviada ao governador do estado, diz que por ter esta autoridade

lhe feito justiça autorizando a compra de seos livros em vez do premio de 25 contos que foi arbitrado, por julgar isto attribuição do Congresso, requer para tornar bem claro o seo direito, determineis a compra do $\mathrm{n}^{\mathbf{o}}$ de exemplares na conformidade da $1^{\mathrm{a}}$ proposta da Inspectoria Geral da Instrução (20 mil a 500 rs) e também na conformidade de vosso respeitável despacho, só para ser pago quando houver a necessária verba. Justiça! ${ }^{36}$

A esse requerimento foram anexados depoimentos de diversas pessoas e entidades, de Ouro Preto e outras cidades de Minas Gerais, impressos na forma de opúsculo, repleto de elogios à qualidade do método e aos resultados alcançados com o mesmo. Os testemunhos atestam a eficiência do Methodo e referem-se ao aprendizado da leitura por parte de crianças e adultos em curto espaço de tempo.

Em 2 de janeiro de 1892, nova investida de Agostinho Penido, escrevendo diretamente ao presidente do estado ao ter notícia de que haviam recursos no orçamento destinados à aquisição de livros: "Alerta! - Alerta estou! Taes as vossas palavras ao povo garantindo

\footnotetext{
${ }^{33}$ MINAS GERAIS. Secretaria do Interior. Fundo Instrução Pública, n. 723, 1892. Arquivo Público Mineiro.

${ }^{34}$ MINAS GERAIS. Secretaria do Interior. Fundo Instrução Pública, n. 881, 1892-1897. Arquivo Público Mineiro.

${ }^{35}$ MINAS GERAIS. Secretaria do Interior. Fundo Instrução Pública, n. 646, 1895. Arquivo Público Mineiro.

${ }^{36}$ MINAS GERAIS. Secretaria do Interior. Fundo Instrução Pública, n. 176, 1892. Arquivo Público Mineiro.
} 
estudo pelas instrucções! Certo do valor das mesmas e por que de o orçamento vigente [constar] verba para livros, proponho a venda de 15 mil exemplares de meo methodo (ultima edição e devidamente corregida) ou o mesmo que for julgado necessario, pelo preço de $1 \$$ [1\$000] cada um"37. Nesse caso, no entanto, a Inspetoria Geral de Instrução Pública de Minas Gerais não oferece boa acolhida ao pedido, remetendo em 11 de janeiro de 1892 a seguinte correspondência ao presidente do estado:

Tenho a honra de vos informar que esse Methodo substitue apenas a cara de $\mathrm{ABC}$ e que não é tanto delle, como de outros livros, como grammaticas, arithmeticas etc., que necessitam as escolas e dos quaes instantemente fazem pedido a esta Repartição. Nestas condições e como dispõe esta Inspectoria ainda de 2500 exemplares do mesmo Methodo, julgo que por enquanto não deve ser feita a acquisição proposta. Entretanto, resolvereis como entenderdes de justiça ${ }^{38}$.

No entanto, Agostinho Penido parecia incansável em sua lida pela circulação de seu método nas escolas estaduais. Provavelmente deve ter feito novos contatos políticos, visando a alteração do parecer acima e, ao que parece, obteve resultados positivos. Em correspondência da Inspetoria de Instrução Pública do Estado de Minas Gerais para o Presidente do estado, de 6 de julho de 1892, é feita referência a despacho do governo, em 28 de junho, seguindo-se uma série de considerações sobre as condições de saúde alegadas por Agostinho Penido ("achar-se enfermo, sem recursos para o seu tratamento, tendo abatido a sua saúde com os grandes esforços que envidou na confecção do citado methodo"), das escolas mineiras e da importância dos livros didáticos para os trabalhos escolares:

tenho a honra de prestar-vos informações a respeito do requerido. Esta repartição ressente-se da absoluta falta de livros didacticos, para ministral-os ás escolas que os reclamam quotidianamente. Frequentada, como é, a maior parte das escolas primarias por meninos pobres, sem recursos para a sua educação, não satisfarão ellas o fim para que foram creadas, de diffundir a instrucção por todas as classes sociaes, sem que lhes sejam ministrados os meios de attingir a esse desideratum, quaes sejam a distribuição gratuita de livros aos alumnos desprotegidos da fortuna. Sem esta condição, será uma anomalia conseguir-se bom resultado do magisterio publico, que se compõe de homens a quem não faltam abnegação e generosidade no desempenho de seo sacerdócio, mas que, tanto como seos alumnos, carecem de recursos pecuniários, porque são mal remunerados. Desta sorte julgo imprescindível que autorizeis a compra não só de um numero sufficiente de exemplares do alludido "Methodo Penido", como também de $2^{\circ}$ e $3^{\circ}$ Livros de leitura de Abilio e João Ribeiro, gramáticas para as escolas normaes, e outros objectos, correndo essa despeza por conta da verba especial de 15:000\$000, de que trata o $\S 4^{\circ}$ do $\operatorname{art.} 1^{\circ}$ da Lei do orçamento vigente ${ }^{39}$.

\footnotetext{
${ }^{37}$ MINAS GERAIS. Secretaria do Interior. Fundo Instrução Pública, n. 723, 1892. Arquivo Público Mineiro.

${ }^{38}$ Idem.

${ }^{39}$ MINAS GERAIS. Secretaria do Interior. Fundo Instrução Pública, n. 176, 1892. Arquivo Público Mineiro.
} 
Em seguida, encontramos uma nova correspondência da Inspetoria para a presidência do estado, de 15 de julho de 1892, fazendo menção a despacho do Presidente, informando que "dos 12.000 livros comprados ao Dr. Agostinho Penido só existem actualmente n'esta Repartição 300 exemplares”. Apesar da preocupação com a verba restante para este tipo de despesa, sugere-se a compra de mais 6.000 exemplares do Methodo Penido e mais 13.000 exemplares de outros livros didáticos ${ }^{40}$.

Em 1893 encontramos nova investida do nosso autor junto ao governo do estado em busca de mais recursos por conta do seu Methodo. Em correspondência à Secretaria do Interior, de 9 de fevereiro de 1893, "appellando para a equidade, peço o mesmo concedido há pouco a grammatica de um colega $(2: 000 \$ 00$ e publicação gratuita da mesma pelo governo) acreditando que ao menos isso será concedido ao suplicante". Em anotação feita ao lado do documento, de 11 de fevereiro de 1893, descobre-se que a solicitação teve rápida acolhida: "Adquiram-se cinco mil exemplares do Methodo Penido, á razão do preço por que foram comprados os últimos exemplares levando porem em abatimento a $20 \%$ " 41 . E em 10 de julho de 1893, encontramos correspondência da Secretaria do Interior para a Secretaria de Finanças, relacionada à Escola Normal de Uberaba, solicitando "pagar ao Sr. Agostinho Penido a quantia de um conto de reis (1:000\$000) importância de livros pelo mesmo fornecidos a esta Secretaria" 42 .

Com relação à circulação do Methodo Penido pelas escolas do estado, existem muitos documentos comprovando o envio de exemplares por parte da Secretaria do Interior para os municípios, para serem distribuídos entre os alunos pobres. Em relatório enviado pelo inspetor ambulante de Uberaba, de 30 de novembro de 1895, após analisar as condições de duas escolas rurais, masculina e feminina, informa-se: "Encontrei adoptados em ambas os seguintes livros: $1^{\circ}, 2^{\circ}, 3^{\circ}$ de leitura de Abilio, Arithmetica e Metrologia de Conturier e de Trajano, Grammatica de J. Brandão e Ortiz e Pascal, e o Methodo de A. Penido"43. Também na imprensa aparecem os comunicados da Secretaria do Interior sobre a remessa de exemplares de livros didáticos. No jornal Minas Geraes, "Orgão Official dos Poderes do Estado", edição de 24 de setembro de 1893, na seção "Actos do Governo do Estado", sob o título de "Livros para as escolas primarias", encontramos a informação de que foram enviados 100 exemplares de cada um dos livros discriminados, para 60 cidades, totalizando de uma só vez 24.000 exemplares, dos quais 6.000 seriam do Methodo Penido: "Pela secretaria do Interior foram remetidos para as escolas primarias dos municípios abaixo mencionados os seguintes exemplares de livros da grammatica portuguesa de João Ribeiro ( $1^{\circ}$ anno); das taboadas de Barcker; da arthmetica de Conturier e do methodo Penido" ${ }^{44}$. Haviam também as remessas diretas para as escolas, comunicadas por correspondência da Secretaria do Interior, como a de 17 de junho de 1895, para o professor Noé Madureira de Oliveira, de Santo Antonio do Rio do Peixe, município do Serro:

\footnotetext{
${ }^{40}$ MINAS GERAIS. Secretaria do Interior. Fundo Instrução Pública, n. 175, 1892. Arquivo Público Mineiro.

${ }^{41}$ MINAS GERAIS. Secretaria do Interior. Fundo Instrução Pública, Serie SI 4-1, n. 229, 1893. Arquivo Público Mineiro.

${ }^{42}$ MINAS GERAIS. Secretaria do Interior. Fundo Instrução Pública, n. 654, 1893. Arquivo Público Mineiro.

${ }^{43}$ MINAS GERAIS. Secretaria do Interior. Fundo Instrução Pública, n. 677, 1895. Arquivo Público Mineiro.

${ }^{44}$ ACTOS do Governo do Estado. Jornal Minas Geraes, ano II, n. 258, 24/09/1893, p. 5.
} 
Remettendo-vos, em nome do Sr. Dr. Secretario do Interior, nesta data, dez exemplares do $3^{\circ}$ livro de leitura de Hilario Ribeiro, dez da arithmetica de R. da Costa e 20 do Methodo Penido, recomendo-vos que façaes delles a distribuição conveniente pelos alumnos pobres da escola a vosso cargo, observadas as disposições dos $\S \S 1^{\circ}$ e $2^{\circ}$, art. 187 , do regulamento de instrução primaria. O Director ${ }^{45}$.

Como esta, existem muitas outras trocas de correspondência entre a Secretaria do Interior e autoridades municipais, relatando o envio de exemplares ou a solicitação dos mesmos, embora a demanda fosse mais abrangente, voltando-se para diversas outras obras de aritmética, língua materna, etc. A imprensa, nas seções voltadas para os atos do governo, também é pródiga nessas informações. E diversas menções são feitas em relatórios dos inspetores escolares do período, como a citada acima, destacando tanto o uso como os elogios que são feitos ao método por parte dos professores das escolas visitadas.

Um último aspecto merece ser destacado: apesar a procura feita por diversas bibliotecas e arquivos de cidades do estado de Minas Gerais, nenhum exemplar remanescente do Methodo Penido foi localizado, o que expõe uma lacuna lamentável para os estudos sobre a escolarização e a alfabetização do início da República brasileira, infelizmente, não observável apenas com relação ao trabalho do professor Penido. Essa lacuna foi anotada também por Isabel Cristina Alves da Silva Frade e Francisca Izabel Pereira Maciel ${ }^{46}$, em trabalho sobre fontes para a história da alfabetização, fazendo referências à circulação desse trabalho em Minas Gerais, mas sem reportar a descoberta de algum exemplar do mesmo. Apesar da impossibilidade de manuseio físico do Methodo Penido, o conjunto dos registros encontrados na documentação nos permite assegurar que o livro teve ampla aceitação e circulação por todo o estado de Minas Gerais, pelo menos na década de 1890.

\section{Considerações finais}

A documentação presente nos arquivos de Minas Gerais nos permite acesso e compreensão de diversos aspectos do passado do estado, notadamente da educação, por conta da quantidade e diversidade de registros que existem, boa parte dos mesmos ainda sem tratamento e a devida interpretação. E, por vezes, essas fontes nos reservam surpresas, felizmente agradáveis no nosso caso. Ao consultar as atas da Câmara Municipal de Ouro Preto e alguns conjuntos documentais do Arquivo Público Mineiro, na busca de elementos que nos permitissem ampliar o conhecimento sobre as relações entre estado e município na organização da instrução pública no início da República, encontramos menções a um mesmo personagem e também a um método de alfabetização, que teria sido inventado por ele. Isso nos levou a um certo "desvio" do propósito original, para nos dedicarmos à busca de elementos complementares que nos permitissem desvendar, ainda que parcialmente, o universo de formação e atuação desse autor de um livro didático aprovado e adotado pelo governo mineiro na primeira década republicana.

Os dados e a historiografia nos auxiliaram a compor o resultado que foi apresentado, necessariamente provisório, por conta das lacunas que ainda precisam ser preenchidas, pela não localização de um exemplar físico do Methodo Penido e pela impossibilidade de ampliar a pesquisa para arquivos de outras cidades ou conjuntos documentais, como a imprensa, etc.

De qualquer forma, cremos ter avançado no debate sobre o processo de constituição dos livros didáticos no final do século XIX, dos desafios enfrentadas pelos autores para

\footnotetext{
${ }^{45}$ MINAS GERAIS. Secretaria do Interior. Fundo Instrução Pública, n. 670, 1895. Arquivo Público Mineiro.

${ }^{46}$ A história da alfabetização: contribuições para o estudo das fontes. In: $29^{a}$ Reunião Anual da ANPED, 2006, Caxambu-MG.
} 
encontrar editores ou para reimprimir seus textos, das dificuldades na comercialização, principalmente com o maior cliente, o estado de Minas Gerais. Vimos, também, como estado e município se aproximam na busca da criação de condições para que o processo de escolarização se institucionalize, às vezes somando esforços, como no caso da proposta de publicação de livros didáticos por parte da Câmara Municipal de Ouro Preto. Ficam patentes, ainda, a importância das relações de influência, ao notarmos que Agostinho Penido, além de empresário foi político, filho de político e obteve formação esmerada tanto no nível secundário como superior.

É importante anotar, finalmente, como os altos índices de analfabetismo presentes em Minas Gerais no início da República, em torno de $80 \%$, colocavam essa como uma das questões centrais nas preocupações das administrações estaduais e municipais que se sucederam nas primeiras décadas republicanas. Por conta disso, bem como pelas motivações das autoridades escolares na busca de alternativas que permitissem superar ou minorar o desafio, o anúncio da invenção de um método quase "milagroso" para se promover a alfabetização, tanto de adultos como de crianças, deve ter alvoraçado parte da elite e também da população, estimulando o governo do estado a investir nessa nova proposta que, além de tudo, fora desenvolvida por um mineiro, que se dispôs, inclusive, a aplica-la experimentalmente na escola que criou sob o patrocínio do estado e colocou em funcionamento já em 1891.

Restam variadas dúvidas e muito terá de ser feito para colocar mais luz nessa iniciativa, tanto para compreender melhor a importância e a difusão do método como também para se promover a crítica sobre a eficácia ou originalidade do mesmo.

\section{Referências}

ACTOS do Governo do Estado. Jornal Minas Geraes, ano II, n. 258, 24/09/1893, p. 5.

BITTENCOURT, Circe Maria Fernandes. Autores e editores de compêndios e livros de leitura (1810-1910). Educação e Pesquisa, v. 30, n. 3, p. 475-491, set./dez. 2004. https://doi.org/10.1590/S1517-97022004000300008

BRASIL. Decreto n. 8248 - DE 3 DE SETEMBRO DE 1881. Disponível em: http://legis.senado.gov.br/legislacao/ListaTextoIntegral.action?id=57457\&norma=73310, consulta em 07/05/2015.

BRASIL. Decreto no 609, de 31 de Julho de 1890. Disponível em: http://www2.camara. leg.br/legin/fed/decret/1824-1899/decreto-609-31-julho-1890-523693-publicacaooriginal-1pe.html, consulta em 07/05/2015.

CÂMARA Municipal de Ouro Preto. Livro de Registro de Atas (resoluções) da Intendência Municipal - 1890-1894. Ouro Preto: Arquivo Municipal de Ouro Preto, Livro n. 894.

CÂMARA Municipal de Ouro Preto Caixa Instrução. Ouro Preto: Arquivo Municipal de Ouro Preto (vários anos).

CÂMARA Municipal de Ouro Preto. Caixa 1892. Ouro Preto: Arquivo Municipal de Ouro Preto.

CARVALHO, Luciana Beatriz de Oliveira Bar de; CARVALHO, Carlos Henrique de. $O$ lugar da educação na modernidade luso-brasileira no fim do século XIX e início do XX. Campinas: Alínea, 2012. 
COLÉGIO do Caraça. Livro de Matrícula 1860. Disponível em: http://www.santuariodocaraca.com.br/livro-de-matricula-1856-1910/livro-de-matricula-1860/. Consulta em 07/05/2015.

COLÉGIO do Caraça. Lista de Ex-alunos. Disponível em: http://www.santuariodocaraca. com.br/lista-de-ex-alunos/lista-de-ex-alunos-letra-a/. Consulta em 07/05/2015.

FRADE, Isabel Cristina Alves da Silva; MACIEL, Francisca Izabel Pereira. A história da alfabetização: contribuições para o estudo das fontes. In: $29^{a}$ Reunião Anual da ANPED, 2006, Caxambu-MG. Disponível em: www.anped.org.br/sites/default/files/gt10-1955-int.pdf (acesso em 18/01/2018).

HISTÓRIA das Minas de Ouro e Diamante: a Lista dos 120 Ex-Alunos do Caraça na Política. Disponível em: http://monlewood.blogspot.com.br/2015/02/historia-das-minas-de-ouro-ediamante.html, consulta em 07/05/2015.

LISBÔA, Venâncio José de Oliveira. Relatório que á Assemblea Legislativa Provincial de Minas Geraes apresentou na sessão ordinária de 1873 o Presidente da Provincia. Disponível em: http://brazil.crl.edu/bsd/bsd/480/000008.html, consulta em 07/05/2015.

MANTOVANI, André Luiz. Faça-se a luz: modernidade e demandas sociais na eletrificação da iluminação pública de Ouro Preto, 1880-1920. Mariana: UFOP, 2005 (monografia de bacharelado).

MARTINS, Henrique. Lista geral dos bachareis e doutores que têm obtido o respectivo gráo na Faculdade de Direito do Recife, desde sua fundação em Olinda no ano de 1828, até o ano de 1931. Recife: Typographia Diario da Manhã, 1931. Disponível em https://www.ufpe.br/ccj/images/bachareis/bacharis\%201828\%20-\%201931.pdf, consulta em 07/05/2015. Cf.

MINAS GERAIS. Lei n. 41 - Dá nova organização á instrucção publica do estado de Minas. Colecção das leis e decretos do estado de Minas Geraes em 1892. Ouro Preto: Imprensa Official de Minas Geraes, 1893.

MINAS GERAIS. Decreto n. 655 - Promulga o regulamento das escolas e instrucção primaria. Colecção das leis e decretos do estado de Minas Geraes em 1893. Ouro Preto: Imprensa Official de Minas Geraes, 1894.

MINAS GERAIS. Secretaria do Interior. Fundo Instrução Pública, n. SG1052, 1890. Arquivo Público Mineiro.

MINAS GERAIS. Secretaria do Interior. Fundo Instrução Pública, n. 670, 1895. Arquivo Público Mineiro.

MINAS GERAIS. Secretaria do Interior. Fundo Instrução Pública, n. 646, 1895. Arquivo Público Mineiro.

MINAS GERAIS. Secretaria do Interior. Fundo Instrução Pública, n. 881, 1892-1897. Arquivo Público Mineiro.

MINAS GERAIS. Secretaria do Interior. Fundo Instrução Pública, n. 723, 1892-1897. Arquivo Público Mineiro. 
MINAS GERAIS. Secretaria do Interior. Fundo Instrução Pública, n. 175, 1892. Arquivo Público Mineiro.

MINAS GERAIS. Secretaria do Interior. Fundo Instrução Pública, n. 176, 1892. Arquivo Público Mineiro.

MINAS GERAIS. Secretaria do Interior. Fundo Instrução Pública, Serie SI 4-1, n. 229, 1893. Arquivo Público Mineiro.

MINAS GERAIS. Secretaria do Interior. Fundo Instrução Pública, n. 654, 1893. Arquivo Público Mineiro.

MINAS GERAIS. Secretaria do Interior. Fundo Instrução Pública, n. 677, 1895. Arquivo Público Mineiro.

MORTATTI, Maria do Rosário Longo. História dos métodos de alfabetização no Brasil (conferência de abertura do Seminário Alfabetização e Letramento em Debate). In: Seminário Alfabetização e Letramento em Debate. Brasília: MEC/SEB, 2006, 16 p.

MORTATTI, Maria do Rosário Longo. A "querela dos métodos" de alfabetização no Brasil: contribuições para metodizar o debate, Revista ACOALFAplp: Acolhendo a Alfabetização nos Países de Língua portuguesa, São Paulo, ano 3, n. 5, 2008, p. 91-114.

MOURÃO, Paulo Krüger Corrêa. O ensino em Minas Gerais no tempo da República. Belo Horizonte: Centro Regional de Pesquisas Educacionais de Minas Gerais, 1962.

NAVA, Pedro. Balão Cativo: memórias/2. Rio de Janeiro: J. Olympio, 1977.

PARTE Official. Diario de Pernambuco, anno L, n. 18, 23 de janeiro de 1874, p. 1. Disponível em: http://ufdc.ufl.edu/AA00011611/17555/1x?vo=3, consulta em 07/05/2015.

PENIDO, Jeronimo Maximo Nogueira. Base de dados de todos os parentes, colaterais e não parentes. Disponível em: http://www.geocities.ws/basededadoscastro/pafg56.html, consulta em 07/05/2015.

SCHUELER, Alessandra Frota M. de; TEIXEIRA, Giselle Baptista. Civilizar a infância: moral em lições no livro escolar de Guilhermina de Azambuja Neves (Corte imperial, 1883). Revista de Educação Pública, v. 17, n. 35, set-dez 2008, p. 563-577.

SOUZA, Rosa Fátima de. Templos de civilização: a implantação da escola primária graduada no Estado de São Paulo (1890-1910). São Paulo: UNESP, 1998.

SUPLLENTES do Juiz Municipal. A Provincia de Minas, Anno VIII, n. 513, 10 de fevereiro de 1888, p. 2. Disponível em: http://memoria.bn.br/DocReader/Hotpage/ HotpageBN.aspx? bib=222747\&pagfis=1314\&url=http://memoria.bn.br/docreader\# (consulta em 18/01/2018). 